\title{
CARBON POOL AND BIOLOGICAL ACTIVITIES OF SOILS IN DIFFERENT ECOSYSTEMS
}

\author{
Olena Demyanyuk ${ }^{1}$, Lyudmyla Symochko ${ }^{2 *}$, Hosam E.A.F. Bayoumi Hamuda ${ }^{3}$, \\ Vitaliy Symochko ${ }^{2}$, Olga Dmitrenko ${ }^{4}$ \\ ${ }^{1}$ Institute of Agroecology and Environmental Management NAAS, Metrologichna Str., 12, Kyiv, 03143, Ukraine; \\ ${ }^{2 *}$ Faculty of Biology, Uzhhorod National University, Voloshyna, 32, Uzhhorod, Transcarpathian region, 88000, Ukraine; \\ $2 * S R \& E$ Center of Molecular Microbiology and the Immunology of Mucous Membranes, Ukraine; \\ ${ }^{3}$ Institute of Environmental Engineering, Obuda University, H-1034, Doberdo Str.6, Budapest, Hungary; \\ ${ }^{4}$ State Institution «Soil Protection Institute of Ukraine», Olena Teligha Str., 8, Kyiv, 04112, Ukraine;
}

Corresponding Author Lyudmyla Symochko, email: 1yudmilassem@gmail.com;

Received December 2018; Accepted January 2019; Published February 2019;

DOI: https://doi.org/10.31407/ijees9122

UOI license: http://u-o-i.org/1.01/ijees/08709384

\begin{abstract}
The content and stocks of carbon and the activity of microbiological destruction of organic matter in three types of chernozem soils in Ukraine have been investigated. An imbalance was found in the accumulation of the main components of the soil organic matter, as well as between mineralization processes, humus accumulation and degradation of cellulose in arable soils and their natural analogs. In the soil of natural ecosystems, the processes of mineralization -immobilization, destruction of organic matter and humus accumulation are balanced, which is confirmed by a high carbon pool $\left(\mathrm{C}_{\mathrm{tot}}\right)$ and a fraction of $\mathrm{C}_{\mathrm{mic}}$ in $\mathrm{C}_{\text {tot }}$. In the soil of natural ecosystems processes of mineralization-immobilization, destruction of organ resources and humus-accumulating are balanced, which is confirmed by high-quality carbon pool and partial $\mathrm{C}_{\text {mic }}$ in $\mathrm{C}_{\text {tot }}$. In agroecosystem is going destabilization of organic matter in the soil, which leads to a decrease of humus content in 1.11.5 times, stocks of organic matter - in 1.3-1.8 times. In arable soils, part of $\mathrm{C}_{\mathrm{org}}$ in the total soil carbon pool is $80-82 \%$ and $92-94 \%$ in the soil of the natural ecosystem. The losses of $\mathrm{C}_{\mathrm{org}}$ from chernozem soils in agroecosystem are 19-29\% and this is due to a significant reduction in the content of $\mathrm{C}_{\text {mic }}(63-71 \%)$. The application of different fertilizers causes destabilization of the soil microbial community, reduces microbial productivity and activates mineralization processes of organic matter, which leads to loss of $\mathrm{C}_{\mathrm{org}}$ and a decrease in the total carbon pool $\left(\mathrm{C}_{\mathrm{tot}}\right)$ in the soil by 6-18\%. The soil of natural ecosystems is characterized by a high content of $\mathrm{C}_{\text {mic }}$ in the $\mathrm{C}_{\mathrm{org}}(3.14-3.70 \%)$, which indicates a high microbial productivity and fixation of organic substances in biomass of microorganisms. In the arable soils, was the low content of $\mathrm{C}_{\text {mic }}$ in the organic matter of the soil (1.19-1.52\%) which indicates the predominance of mineralization processes over the processes of humification. The application of exogenous mineral substances in the soil activates the processes of mineralization $\left(K_{\min }\right.$ increases by $\left.7-18 \%\right)$ and provides a high degree of using by microorganisms of soil organic matter ( $\kappa_{\text {ped }}$ increases by 6-9\%). Organic fertilizers contribute to the formation of a maximum microbial pool, optimizing the structure of soil microbial community, decrease the intensity of mineralization processes $\left(\kappa_{\min }\right)$ by $15-29 \%$ and the decomposition of soil organic matter by 6 to 37\%. A significant difference in the parameters of the potential cellulolytic activity of the soil in the natural ecosystems and agroecosystems had been established. At the same time, the soil of natural ecosystems is characterized by a slight fluctuation of the emission $\mathrm{CO}_{2}\left(3.3-4.4 \mathrm{mg} \mathrm{CO}_{2} / \mathrm{kg}\right.$ of soils per day).
\end{abstract}

Keywords: chernozem, fertilizer system, carbon pool, soil organic matter, ratio $\mathrm{C}_{\text {mic }} / \mathrm{C}_{\text {org }}$, microbiological activity, $\mathrm{CO}_{2}$ emission, destruction of cellulose. 